\title{
Cutaneous Adverse Events in Newly Approved FDA Non-cancer Drugs: A Systematic Review
}

\author{
Paul C. Macklis ${ }^{1} \cdot$ Brittany Dulmage ${ }^{1} \cdot$ Brady Evans $^{1} \cdot$ Misha Rosenbach $^{2} \cdot$ Johann E. Gudjonsson $^{3}$. \\ Benjamin H. Kaffenberger ${ }^{1}$ (D)
}

Published online: 17 June 2020

(c) The Author(s) 2020

\begin{abstract}
The prevalence of cutaneous adverse events attributable to newly approved anti-cancer drugs has been well reviewed in the dermatologic literature. In contrast, over 75\% of US Food and Drug Administration approvals in the past 5 years have been for non-cancer drugs and indications. This represents multiple other categories of approved medications associated with cutaneous adverse reactions. To investigate the cutaneous adverse events associated with these potentially neglected medications, a systematic review was conducted. Two hundred and forty-one medications approved by the Food and Drug Administration between 2013 and 2018 were reviewed and 180 non-oncologic drugs were identified. The prescribing information for each medication was reviewed for the presence of cutaneous adverse events and a supplemental literature search was performed to better characterize any adverse events outlined within the prescribing information. Most reactions were classified as morbilliform, macular, popular, or maculopapular. Fortunately, only a few severe cutaneous adverse reactions were reported, namely in benznidazole, cannabidiol, and sofosbuvir. This review summarizes available data drawn from clinical trials and case reports involving cutaneous adverse events from the 21 non-oncologic medications associated with cutaneous adverse events.
\end{abstract}

\section{Key Points}

One hundred and eighty non-oncologic medications received US Food and Drug Administration approval between 2013 and 2018.

Twenty-one of these medications were associated with cutaneous adverse events from mild rashes to severe reactions including Stevens-Johnson syndrome.

Clinicians should consider these newly approved medications when managing cutaneous pathologies.

Benjamin H. Kaffenberger

Benjamin.Kaffenberger@osumc.edu

1 Division of Dermatology, Department of Internal Medicine, The Ohio State University Wexner Medical Center, 2012 Kenny Road, Rm 232, Columbus, OH 43212, USA

2 Department of Dermatology, Perelman School of Medicine, University of Pennsylvania, Philadelphia, PA, USA

3 Department of Dermatology, University of Michigan Medical School, Ann Arbor, MI, USA

\section{Introduction}

In the past 5 years, over 40 new medications or new indications have been approved yearly by the US Food and Drug Administration (FDA), presenting a formidable task for dermatologists to remain current with dermatologic adverse events of these newly FDA-approved therapies. Fortunately, numerous reviews have highlighted adverse events among new therapies with cancer indications [1-3]. However, that represents fewer than $25 \%$ of all new approvals or new indications. This article reviews the adverse cutaneous side effects of all non-cancer FDA-approved medications released between 2013 and 2018.

\section{Methodology}

Drugs approved by the FDA between 2013 and 2018 were systematically reviewed directly from the FDA website's database, and a list of the 241 medications and their approved indications was created (Table 1). Subsequently, 61 medications with cancer indications were removed. Then, the prescribing information package inserts for the remaining 180 drugs were reviewed and evaluated for mention of 
Table 1 All medications approved by the US Food and Drug Administration between 2013 and 2018

\begin{tabular}{|c|c|c|}
\hline Generic & Brand & Indication \\
\hline \multicolumn{3}{|l|}{2013} \\
\hline Afatinib & Gilotrif & Non-small cell lung cancer \\
\hline Alogliptin & Nesina & Type 2 diabetes mellitus \\
\hline Canagliflozin & Invokana & Type 2 diabetes mellitus \\
\hline Conjugated estrogens and bazedoxifene & Duavee & Menopause \\
\hline Dabrafenib & Tafinlar & Cancers with $B R A F$ gene mutation \\
\hline Dimethyl fumarate & Tecfidera & Multiple sclerosis \\
\hline Dolutegravir & Tivicay & HIV \\
\hline Eslicarbazepine & Aptiom & Partial-onset seizures \\
\hline Flutemetamol & Vizamyl & Alzheimer disease \\
\hline Fluticasone furoate and vilanterol & Breo Ellipta & Chronic obstructive pulmonary disease \\
\hline Gadoteric acid & Dotarem & Gadolinium-based contrast agent used with MRI \\
\hline Ibrutinib & Imbruvica & $\begin{array}{l}\text { Mantle cell lymphoma, chronic lymphocytic leukemia/small } \\
\text { lymphocytic lymphoma, Waldenstrom macroglobulinemia }\end{array}$ \\
\hline luliconazole & Luzu & Tinea pedis, tinea cruris, and tinea corporis \\
\hline Macitentan & Opsumit & Pulmonary arterial hypertension \\
\hline Mipomersen & Kynamro & Familial hypercholesterolemia \\
\hline Obinutuzumab & Gazyva & Chronic lymphocytic leukemia and follicular lymphoma \\
\hline Ospemifene & Osphena & Painful intercourse and vaginal dryness \\
\hline Pomalidomide & Pomalyst & Multiple myeloma \\
\hline Radium-223 & Xofigo & Prostate cancer \\
\hline Riociguat & Adempas & Chronic thromboembolic pulmonary hypertension \\
\hline Simeprevir & Olysio & Hepatitis $\mathrm{C}$ virus \\
\hline Sofosbuvir & Sovaldi & Hepatitis $\mathrm{C}$ virus \\
\hline Technetium Tc 99 m tilmanocept & Lymphoseek & Lymphatic mapping in patients with solid tumors \\
\hline Trametinib & Mekinist & Cancer in people who have a ' $B R A F$ ' gene mutation \\
\hline Trastuzumab emtansine & Kadcyla & HER2-positive breast cancer \\
\hline Umeclidinium bromide & Anoro Ellipta & Chronic obstructive pulmonary disease \\
\hline Vortioxetine & Brintellix & Major depression \\
\hline \multicolumn{3}{|l|}{2014} \\
\hline Albiglutide & Tanzeum & Type 2 diabetes mellitus \\
\hline Apremilast & Otezla & Arthritis \\
\hline Belinostat & Beleodaq & Peripheral T-cell lymphoma \\
\hline Blinatumomab & Blincyto & Acute lymphoblastic leukemia \\
\hline Ceftolozane & Zerbaxa & $\begin{array}{l}\text { Complicated intra-abdominal infections and complicated uri- } \\
\text { nary tract infections }\end{array}$ \\
\hline Ceritinib & Zykadia & Non-small cell lung cancer \\
\hline Dalbavancin & Dalvance & Skin infections \\
\hline Dapagliflozin & Farxiga & Type 2 diabetes mellitus \\
\hline Dasabuvir & Viekira Pak & Hepatitis $\mathrm{C}$ virus \\
\hline Droxidopa & Northera & Dizziness or a light-headed feeling \\
\hline Dulaglutide & Trulicity & Type 2 diabetes mellitus \\
\hline Efinaconazole & Jublia & Onychomycosis \\
\hline Eliglustat & Cerdelga & Type 1 Gaucher disease \\
\hline Elosulfase alfa & Vimzim & Mucopolysaccharidosis IV type A \\
\hline Empagliflozin & Jardiance & Type 2 diabetes mellitus \\
\hline Finafloxacin & Xtoro & Acute otitis externa \\
\hline Idelalisib & Zydelig & Chronic lymphocytic leukemia \\
\hline Ledipasvir & Harvoni & Hepatitis $\mathrm{C}$ virus \\
\hline Metreleptin & Myalept & Leptin deficiency \\
\hline
\end{tabular}


Table 1 (continued)

\begin{tabular}{|c|c|c|}
\hline Generic & Brand & Indication \\
\hline Miltefosine & Impavido & Leishmaniasis \\
\hline Naloxegol & Movantik & Constipation that is caused by opioids \\
\hline Netupitant & Akynzeo & Nausea and vomiting caused by chemotherapy \\
\hline Nintedanib & Ofev & Idiopathic pulmonary fibrosis \\
\hline Nivolumab & Opdivo & Non-small cell lung cancer \\
\hline Olaparib & Lymparza & Ovarian cancer \\
\hline Olodaterol & Striverdi Respimat & Chronic obstructive pulmonary disease \\
\hline Ombitasvir & Viekira Pak & Hepatitis $\mathrm{C}$ virus \\
\hline Oritavancin & Orbactiv & Bacterial skin and skin structure infections \\
\hline Paritaprevir & Viekira Pak & Hepatitis $\mathrm{C}$ virus \\
\hline Peginterferon beta-1a & Plegridy & Relapsing forms of multiple sclerosis \\
\hline Pembrolizumab & Keytruda & Melanoma \\
\hline Peramivir & Rapivab & Influenza \\
\hline Pirfenidone & Esbriet & Idiopathic pulmonary fibrosis \\
\hline Ramucirumab & Cyramza & $\begin{array}{l}\text { Stomach cancer, colorectal cancer, or non-small cell } \\
\text { lung cancer }\end{array}$ \\
\hline Siltuximab & Sylvant & Multicentric Castleman disease \\
\hline Suvorexant & Belsomra & Insomnia \\
\hline Tasimelteon & Hetlioz & Non-24-h sleep-wake disorder \\
\hline Tavaborole & Kerydin & Onychomycosis \\
\hline Tazobactam & Zerbaxa & Drug-resistant bacteria \\
\hline Tedizolid & Sivextro & MRSA infections \\
\hline Vedolizumab & Entyvio & Ulcerative colitis and Crohn disease \\
\hline Vorapaxar & Zontivity & Lower the risk of stroke or serious heart problems \\
\hline \multicolumn{3}{|l|}{2015} \\
\hline Alectinib & Alecensa & Anaplastic lymphoma kinase-positive lung cancer \\
\hline Alirocumab & Praluent & High cholesterol \\
\hline Aripiprazole lauroxil & Aristada & Schizophrenia \\
\hline Asfotase alfa & Strensiq & Perinatal, infantile, and juvenile-onset hypophosphatasia \\
\hline Brexpiprazole & Rexulti & Schizophrenia \\
\hline Cangrelor & Kengreal & Prevent the formation of harmful blood clots \\
\hline Cariprazine & Vraylar & schizophrenia \\
\hline Ceftazidime-avibactam & Avycaz & Complicated intra-abdominal infections \\
\hline Cholic acid & Cholbam & Bile acid synthesis disorders \\
\hline Cobimetinib & Cotellic & Melanoma \\
\hline Daclatasvir & Daklinza & Hepatitis $\mathrm{C}$ virus \\
\hline Daratumumab & Darzalex & Multiple myeloma \\
\hline Deoxycholic acid & Kybella & Moderate-to-severe fat below the chin \\
\hline Dinutuximab & Unituxin & Neuroblastoma \\
\hline Edoxaban & Savaysa & Stroke and dangerous blood clots \\
\hline Elotuzumab & Empliciti & Multiple myeloma \\
\hline Eluxadoline & Viberzi & Irritable bowel syndrome with diarrhea \\
\hline $\begin{array}{l}\text { Elvitegravir, cobicistat, emtricitabine, and tenofovir } \\
\text { alafenamide }\end{array}$ & Genvoya & HIV \\
\hline Evolocumab & Repatha & High cholesterol \\
\hline Flibanserin & Addyi & Generalized hypoactive sexual desire disorder \\
\hline Idarucizumab & Praxbind & Reverse Pradaxa's blood-thinning effects \\
\hline Insulin degludec injection & Tresiba & Diabetes mellitus \\
\hline Isavuconazonium sulfate & Cresemba & Invasive aspergillosis and invasive mucormycosis \\
\hline Ivabradine & Corlanor & Heart failure \\
\hline
\end{tabular}


Table 1 (continued)

\begin{tabular}{|c|c|c|}
\hline Generic & Brand & Indication \\
\hline Ixazomib & Ninlaro & Multiple myeloma \\
\hline Lenvatinib & Lenvima & Differentiated thyroid cancer \\
\hline Lesinurad & Zurampic & Gout \\
\hline Lumacaftor $200 \mathrm{mg}$ /ivacaftor $125 \mathrm{mg}$ & Orkambi & Cystic fibrosis \\
\hline Mepolizumab & Nucala & Asthma \\
\hline Necitumumab & Portrazza & Squamous non-small cell lung cancer \\
\hline Osimertinib & Tagrisso & Non-small cell lung cancer \\
\hline Palbociclib & Ibrance & Breast cancer \\
\hline Panobinostat & Farydak & Multiple myeloma \\
\hline Parathyroid hormone & Natpara & Hypocalcemia \\
\hline Patiromer for oral suspension & Veltassa & Hyperkalemia \\
\hline Rolapitant & Varubi & Delayed-phase chemotherapy-induced nausea and vomiting \\
\hline Sacubitril/valsartan & Entresto & Heart failure \\
\hline Sebelipase alfa & Kanuma & Lysosomal acid lipase deficiency \\
\hline Secukinumab & Cosentyx & Plaque psoriasis \\
\hline Selexipag & Uptravi & Pulmonary arterial hypertension \\
\hline Sonidegib & Odomzo & Basal cell carcinoma \\
\hline Sugammadex & Bridion & Reverse effects of neuromuscular blocking drugs \\
\hline Trabectedin & Yondelis & Soft-tissue sarcomas \\
\hline Trifluridine and tipiracil & Lonsurf & Colorectal cancer \\
\hline Uridine triacetate & Xuriden & Hereditary orotic aciduria \\
\hline \multicolumn{3}{|l|}{2016} \\
\hline Atezolizumab & Tecentriq & Urothelial carcinoma \\
\hline Bezlotoxumab & Zinplava & Clostridium difficile \\
\hline Brivaracetam & Briviact & Partial-onset seizures \\
\hline Crisaborole & Eucrisa & Mild-to-moderate eczema \\
\hline Daclizumab & Zinbryta & Multiple sclerosis \\
\hline Defibrotide sodium & Defitelio & Hepatic veno-occlusive disease \\
\hline Elbasvir and grazoprevir & Zepatier & Hepatitis $C$ virus \\
\hline Eteplirsen & Exondys 51 & Duchenne muscular dystrophy \\
\hline Fluciclovine F 18 & Axumin & Prostate cancer \\
\hline Gallium Ga 68 dotatate & NETSPOT & Neuroendocrine tumors \\
\hline Ixekizumab & Taltz & Plaque psoriasis \\
\hline Lifitegrast ophthalmic solution & Xiidra & Dry eye disease \\
\hline Lixisenatide & Adlyxin & Glycemic control (blood sugar levels) \\
\hline Nusinersen & Spinraza & Spinal muscular atrophy \\
\hline Obeticholic acid & Ocaliva & Chronic liver disease \\
\hline Obiltoxaximab & Anthim & Anthrax \\
\hline Olaratumab & Lartruvo & Soft-tissue sarcoma \\
\hline Pimavanserin & Nuplazid & $\begin{array}{l}\text { Hallucinations and delusions associated with Parkinson } \\
\text { disease }\end{array}$ \\
\hline Reslizumab & Cinqair & Asthma \\
\hline Rucaparib & Rubraca & Ovarian cancer \\
\hline Sofosbuvir and velpatasvir & Epclusa & Hepatitis $C$ virus \\
\hline Venetoclax & Venclexta & Chronic lymphocytic leukemia \\
\hline \multicolumn{3}{|l|}{2017} \\
\hline Abaloparatide & Tymlos & Osteoporosis \\
\hline Abemaciclib & Verzenio & Breast cancers \\
\hline Acalabrutinib & Calquence & Mantle cell lymphoma \\
\hline Angiotensin II & Giapreza & Septic or other distributive shock \\
\hline
\end{tabular}


Table 1 (continued)

\begin{tabular}{|c|c|c|}
\hline Generic & Brand & Indication \\
\hline Avelumab & Bavencio & Merkel cell carcinoma \\
\hline Benralizumab & Fasenra & Asthma \\
\hline Benznidazole & Benznidazole & Chagas disease \\
\hline Betrixaban & Bevyxxa & Venous thromboembolism \\
\hline Brigatinib & Alunbrig & $\begin{array}{l}\text { Anaplastic lymphoma kinase-positive metastatic non-small } \\
\text { cell lung cancer }\end{array}$ \\
\hline Brodalumab & Siliq & Moderate-to-severe plaque psoriasis \\
\hline Cerliponase alfa & Brineura & Batten disease \\
\hline Copanlisib & Aliqopa & Relapsed follicular lymphoma \\
\hline Deflazacort & Emflaza & Duchenne muscular dystrophy \\
\hline Delafloxacin & Baxdela & Bacterial skin infections \\
\hline Deutetrabenazine & Austedo & Chorea from Huntington disease \\
\hline Dupilumab & Dupixent & Eczema \\
\hline Durvalumab & Imfinzi & Urothelial carcinoma \\
\hline Edaravone & Radicava & Amyotrophic lateral sclerosis \\
\hline Emicizumab & Hemlibra & Hemophilia A \\
\hline Enasidenib & Idhifa & Acute myeloid leukemia \\
\hline Ertugliflozin & Steglatro & Type 2 diabetes mellitus \\
\hline Etelcalcetide & Parsabiv & Secondary hyperparathyroidism \\
\hline Glecaprevir and pibrentasvir & Mavyret & Hepatitis $\mathrm{C}$ virus \\
\hline Guselkumab & Tremfya & Plaque psoriasis \\
\hline Inotuzumab ozogamicin & Besponsa & Acute lymphoblastic leukemia \\
\hline Latanoprostene bunod ophthalmic solution & Vyzulta & Open-angle glaucoma \\
\hline Lzetermovir & Prevymis & Prevent infection after bone marrow transplant \\
\hline Macimorelin acetate & Macrilen & Growth hormone deficiency \\
\hline Meropenem and vaborbactam & Vabomere & Complicated urinary tract infections \\
\hline Midostaurin & Rydapt & Acute myeloid leukemia \\
\hline Naldemedine & Symproic & Opioid-induced constipation \\
\hline Neratinib maleate & Nerlynx & Breast cancer \\
\hline Netarsudil & Rhopressa & Glaucoma \\
\hline Niraparib & Zejula & $\begin{array}{l}\text { Epithelial ovarian, fallopian tube, or primary peritoneal } \\
\text { cancers }\end{array}$ \\
\hline Ocrelizumab & Ocrevus & $\begin{array}{l}\text { Relapsing and primary progressive forms of multiple scle- } \\
\text { rosis }\end{array}$ \\
\hline Ozenoxacin & Xepi & Impetigo \\
\hline Plecanatide & Trulance & Chronic idiopathic constipation \\
\hline Ribociclib & Kisqali & Breast cancer \\
\hline Safinamide & Xadago & Parkinson disease \\
\hline Sarilumab & Kevzara & Rheumatoid arthritis \\
\hline Secnidazole & Solosec & Bacterial vaginosis \\
\hline Semaglutide & Ozempic & Type 2 diabetes mellitus \\
\hline Sofosbuvir, velpatasvir, and voxilaprevir & Vosevi & Hepatitis $\mathrm{C}$ virus \\
\hline Telotristat ethyl & Xermelo & Carcinoid syndrome diarrhea \\
\hline Valbenazine & Ingrezza & Tardive dyskinesia \\
\hline Vestronidase alfa-vjbk & Mepsevii & Mucopolysaccharidosis type VII also known as Sly syndrome \\
\hline \multicolumn{3}{|l|}{2018} \\
\hline Amifampridine & Firdapse & Lambert-Eaton myasthenic syndrome \\
\hline Apalutamide & Erleada & Prostate cancer \\
\hline Avatrombopag & Doptelet & Thrombocytopenia \\
\hline Baloxavir marboxil & Xofluza & Influenza \\
\hline
\end{tabular}


Table 1 (continued)

\begin{tabular}{|c|c|c|}
\hline Generic & Brand & Indication \\
\hline Baricitinib & Olumiant & Rheumatoid arthritis \\
\hline Bictegravir, embitcitabine, tenofovir alafenamide & Biktarvy & HIV \\
\hline Binimetinib & Mektovi & Melanoma \\
\hline Burosumab-twza & Crysvita & $\mathrm{X}$-linked hypophosphatemia \\
\hline Calaspargase pegol-mknl & Asparlas & Acute lymphoblastic leukemia \\
\hline Cannabidiol & Epidioloex & Epilepsy \\
\hline Cemiplimab-rwlc & Libtayo & Squamous cell carcinoma \\
\hline Cenegermin-bkbj & Oxervate & Neurotrophic keratitis \\
\hline Dacomitinib & Vizimpro & Non-small-cell lung cancer \\
\hline Doravirine & Pifeltro & HIV \\
\hline Duvelisib & Copiktra & Chronic lymphocytic leukemia \\
\hline Elagolix sodium & Orilissa & Endometriosis \\
\hline Elapegademase-lvlr & Revcovi & Adenosine deaminase severe combined immunodeficiency \\
\hline Emapalumab-lzsgemapalumab-lzsg & Gamifant & Hemophagocytic lymphohistiocytosis \\
\hline Encorafenib & Braftovi & Melanoma \\
\hline Eravacycline & Xerava & Intra-abdominal infections \\
\hline Erenumab-aooe & Aimovig & Migraine \\
\hline Fish oil triglycerides & Omegaven & Parenteral nutrition \\
\hline Fosnetupitant and palonosetron & Akynzeo & Chemotherapy-induced nausea and vomiting \\
\hline Fostamatinib & Tavalisse & Chronic immune thrombocytopenia \\
\hline Fremanezumab-vfrm & Ajovy & Migraine \\
\hline Galcanezumab-gnlm & Emgality & Migraine \\
\hline Gilteritinib & Xospata & Acute myeloid leukemia \\
\hline Glasdegib & Daurismo & Acute myeloid leukemia \\
\hline Ibalizumab-uiyk & Trogarzo & HIV \\
\hline Inotersen & Tegsedi & $\begin{array}{l}\text { Polyneuropathy of hereditary transthyretin-mediated amyloi- } \\
\text { dosis }\end{array}$ \\
\hline Ivosidenib & Tibsovo & Acute myeloid leukemia \\
\hline Lanadelumab & Takhzyro & Hereditary angioedema \\
\hline Larotrectinib & Vitrakvi & Cancers with a specific biomarker \\
\hline Lofexidine hydrochloride & Lucemyra & Opioid withdrawal \\
\hline Lorlatinib & Lorbrena & Non-small cell lung cancer \\
\hline Lusutrombopag & Mulpleta & Thrombocytopenia \\
\hline Lutetium Lu 177 dotatate & Lutathera & Gastroenteropancreatic neuroendocrine tumors \\
\hline Migalastat & Galafold & Fabry disease \\
\hline Mogamulizumab-kpkc & Poteligeo & Non-Hodgkin lymphoma \\
\hline Moxetumomab pasudotox-tdfk & Lumoxiti & Hairy cell leukemia \\
\hline Moxidectin & Moxidectin & Onchocerciasis \\
\hline Omadacycline & Nuzyra & Bacterial pneumonia and skin infections \\
\hline Patisiran & Onpattro & Hereditary transthyretin-mediated amyloidosis \\
\hline Pegvaliase-pqpz & Palynziq & Phenylketonuria \\
\hline Plazomicin & Zemdri & Complicated urinary tract infections \\
\hline Prucalopride & Motegrity & Chronic idiopathic constipation \\
\hline Ravulizumab & Ultomiris & Paroxysmal nocturnal hemoglobinuria \\
\hline Revefenacin & Yupelri & Chronic obstructive pulmonary disease \\
\hline Rifamycin & Aemcolo & Travelers' diarrhea \\
\hline Sarecycline & Seysara & Acne vulgaris \\
\hline Segesterone acetate and ethinyl estradiol vaginal system & Annovera & Contraception \\
\hline Sodium zirconium cyclosilicate & Lokelma & Hyperkalemia \\
\hline Stiripentol & Diacomit & Dravet syndrome \\
\hline
\end{tabular}


Table 1 (continued)

\begin{tabular}{lll}
\hline Generic & Brand & Indication \\
\hline Tafenoquine & Krintafel & Plasmodium vivax malaria \\
Tagraxofusp-erzs & Elzonris & Blastic plasmacytoid dendritic cell neoplasm \\
Talazoparib & Talzenna & Patients with breast cancer with a germline BRCA mutation \\
Tecovirimat & TPOXX & Smallpox \\
Tezacaftor; ivacaftor & Symdeko & Cystic fibrosis \\
Tildrakizumab & Ilumya & Plaque psoriasis \\
\hline
\end{tabular}

HER2 human epidermal growth factor receptor 2, HIV human immunodeficiency virus, MRI magnetic resonance imaging, MRSA methicillinresistant Staphylococcus aureus

any cutaneous adverse reactions. Medications that produced cutaneous adverse events other than injection-site reactions in more than $5 \%$ of patients from pivotal clinical trials or the package insert were included in the study, resulting in the ultimate inclusion of 21 medications (Fig. 1). Subsequently, a supplemental literature review was performed using the PubMed search engine and MEDLINE database to better characterize the rash using the search terms: "Drug Name", AND rash, OR cutaneous, OR dermatitis. The relevant articles were evaluated and any mention of an adverse cutaneous event was extracted and summarized. Of note, the literature review conducted for this study included an emphasis on rashes rather than subjective complaints such as pruritus. References from the articles were cross-checked and additional articles were added if not found in the search strategy.

\section{Systematic Review of Drug-Related Cutaneous Adverse Events}

Table 2 reviews monoclonal antibody medications approved between 2013 and 2018 with reported adverse cutaneous events in greater than $5 \%$ of patients. Table 3 reviews smallmolecule medications approved between 2013 and 2018 that reported adverse cutaneous events in greater than $5 \%$ of patients.

\subsection{Monoclonal Antibodies}

\subsubsection{Daclizumab (Zinbryta)}

Daclizumab was previously approved in 1997 under the brand name Zenapax to prevent organ rejection in de novo allogenic renal transplant recipients [4]. This form of daclizumab was associated with the development of acne seen in $8.9 \%$ of patients taking daclizumab vs $7.2 \%$ of patients using placebo [4]. However, this form of daclizumab was ultimately discontinued in 2009 because of diminishing market demand rather than safety concerns [5]. In 2016, daclizumab was approved for the treatment of multiple sclerosis.
However, daclizumab was voluntarily removed from the market owing to reports of encephalitis associated with its use [6].

Daclizumab binds to CD25, a high-affinity interleukin (IL)-2 receptor subunit on $\mathrm{T}$ cells, to prevent IL-2-mediated T-cell activation in patients with multiple sclerosis [7]. Rashes were seen in $7 \%$ of patients taking daclizumab during clinical trials vs $3 \%$ of patients taking placebo. Details of the clinical trial indicate that the observed rash was described as an erythematous rash, exfoliative rash, macular rash, maculopapular rash, papular rash, pruritic rash, rash, and vesicular rash [8]. Additional details are limited; however, a supplementary case series also demonstrated an urticarial papulovesicular rash occurring roughly 3 months after discontinuation of daclizumab [9]. While this drug is immunosuppressive, it is possible that a wide variety of morbilliform hypersensitivity reactions may be seen due to an additional loss or delayed loss of immune tolerance from an off-target decrease in T-regulatory cells also displaying the CD25 antigen [7].

\subsubsection{Dupilumab (Dupixent ${ }^{\circledR}$ )}

Dupilumab, approved in 2017, is a medication used to treat eczema. It inhibits IL-4 and IL-13 signaling by specifically binding to the IL-4R $\alpha$ subunit shared by the IL-4 and IL-13 receptor complexes. While the clinical trials did not reveal any novel cutaneous adverse events apart from injectionsite reactions, which were seen in $10 \%$ of patients taking dupilumab compared with $6 \%$ of patients taking placebo [10], a recent case series describes a paradoxical head and neck erythema in seven patients after taking dupilumab for 10-39 weeks [11]. Both clinical and histopathological findings suggested that these were drug-induced skin reactions. A multi-institution retrospective medical record review revealed that dupilumab-induced facial redness was seen in approximately $10 \%$ of patients treated with dupilumab in daily practice [12]. A French national retrospective study found that approximately $4 \%$ of patients taking dupilumab developed head and neck dermatitis [13]. A recent case 


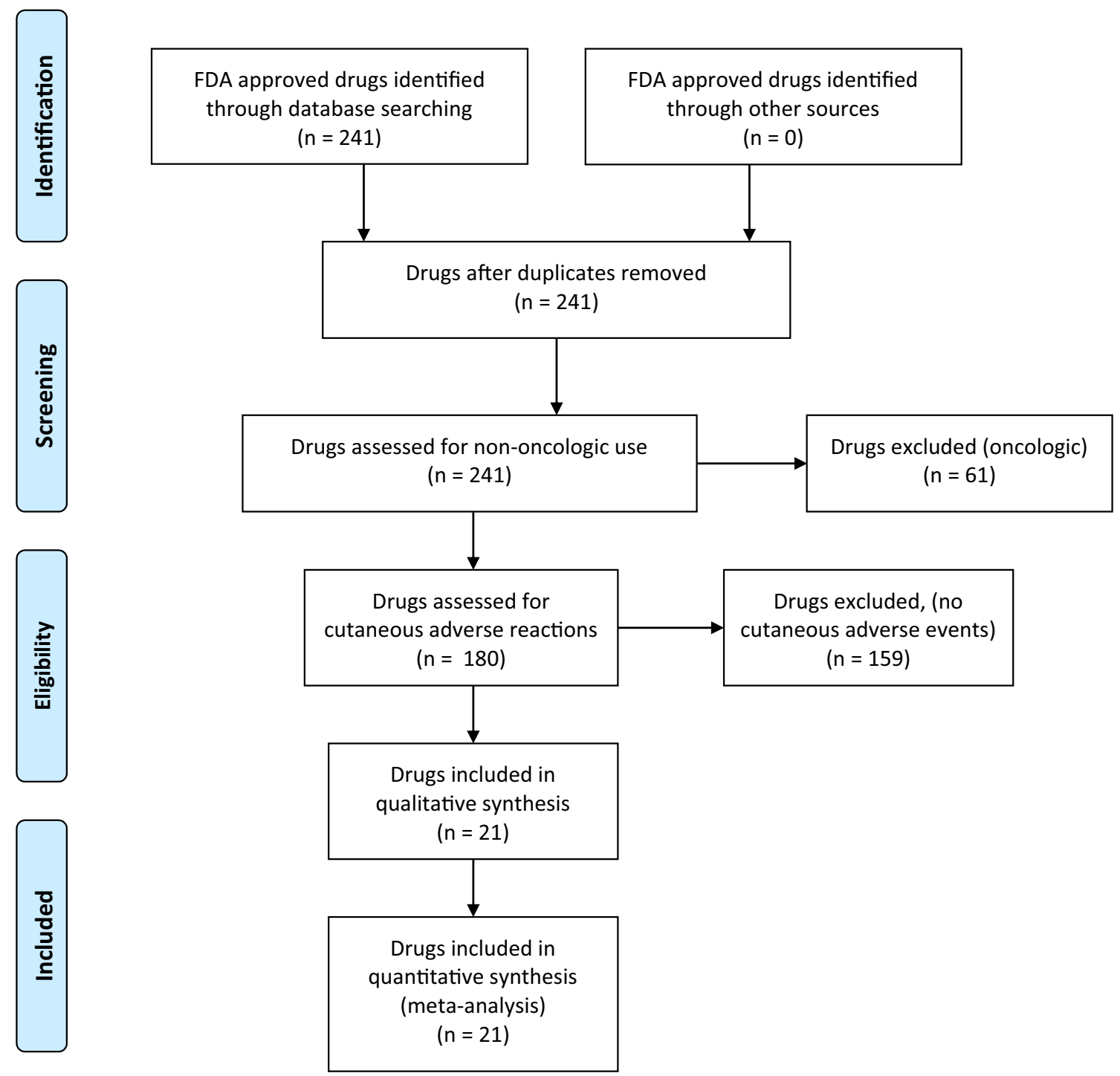

Fig. 1 PRISMA (Preferred Reporting Items for Systematic Reviews and Meta-Analyses) diagram detailing the systematic review process. FDA US Food and Drug Administration

report has suggested that this dupilumab-induced facial redness is attributable to hypersensitivity to Malassezia species and advocates for the use of oral itraconazole in the management of this symptom [14]. Yet another case report describes systemic sarcoid-like granulomatosis occurring 4 months after initiation of dupilumab therapy [15].

\subsubsection{Ibalizumab-uiyk (Trogarzo ${ }^{\oplus}$ )}

Ibalizumab-uiyk was approved in 2018 for the treatment of human immunodeficiency virus. It is a fusion inhibitor, blocking the human immunodeficiency virus- 1 virus from infecting CD4+ T cells by binding to domain 2 of CD4. This interferes with post-attachment steps required for the entry of human immunodeficiency virus-1 particles into host cells, thus preventing the viral transmission that occurs via cell-cell fusion. Rashes were seen in 5\% of patients taking ibalizumab-uiyk during clinical trials and were described as a rash, erythematous rash, generalized rash, macular rash, maculopapular rash, and papular rash [16]. Supplemental case reports have not been published to further describe the skin adverse events.

\subsubsection{Siltuximab (Sylvant ${ }^{\oplus}$ )}

Approved in 2014, siltuximab is a medication used to treat multicentric Castleman disease. It binds to IL-6, thereby preventing its association with both soluble and membranebound IL-6 receptors. Rashes were seen in $28 \%$ of patients taking siltuximab during clinical trials vs $12 \%$ of patients 


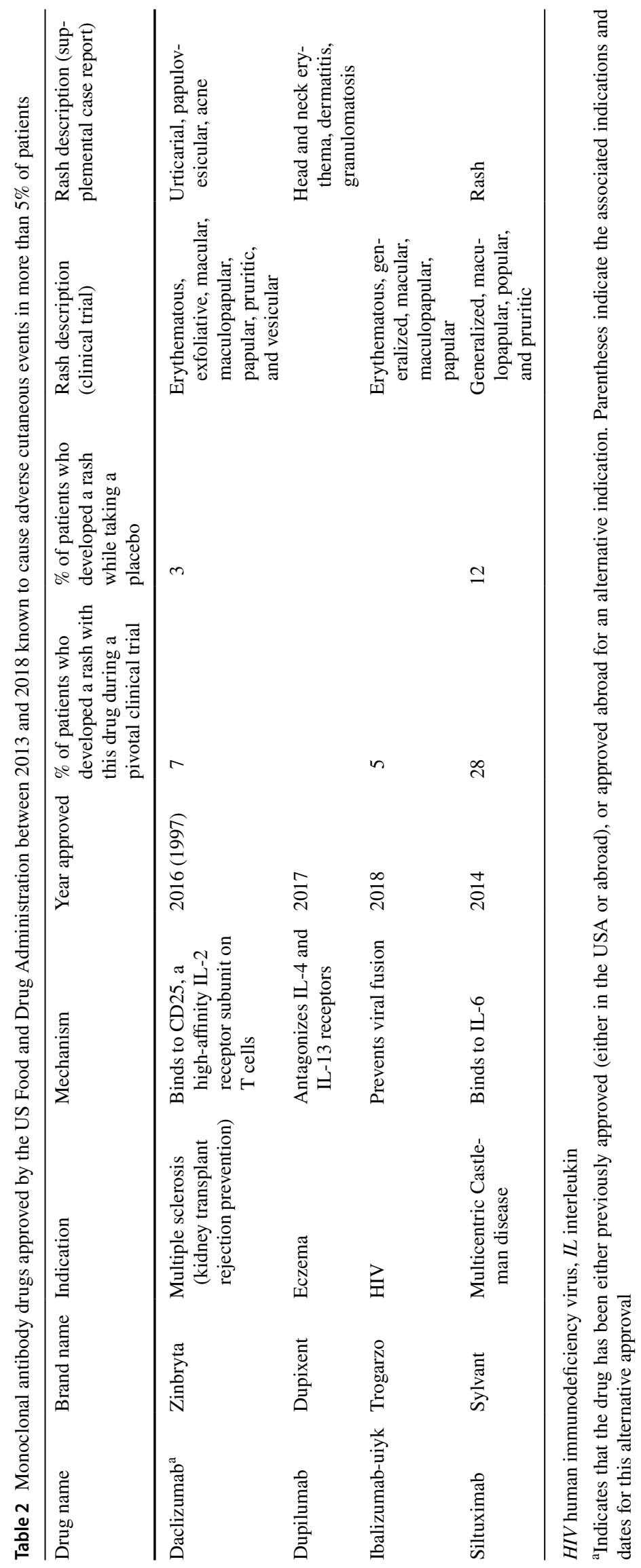




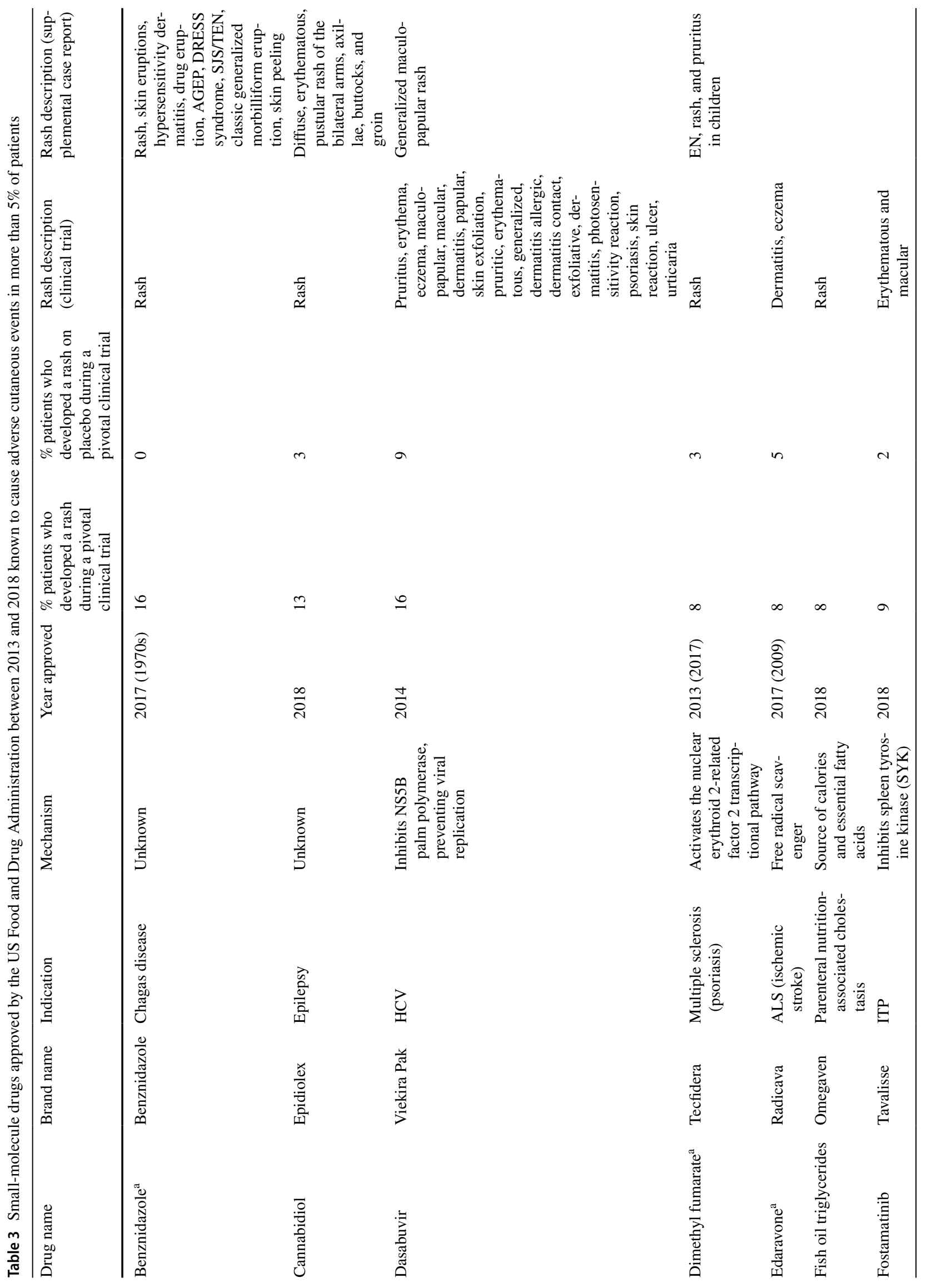




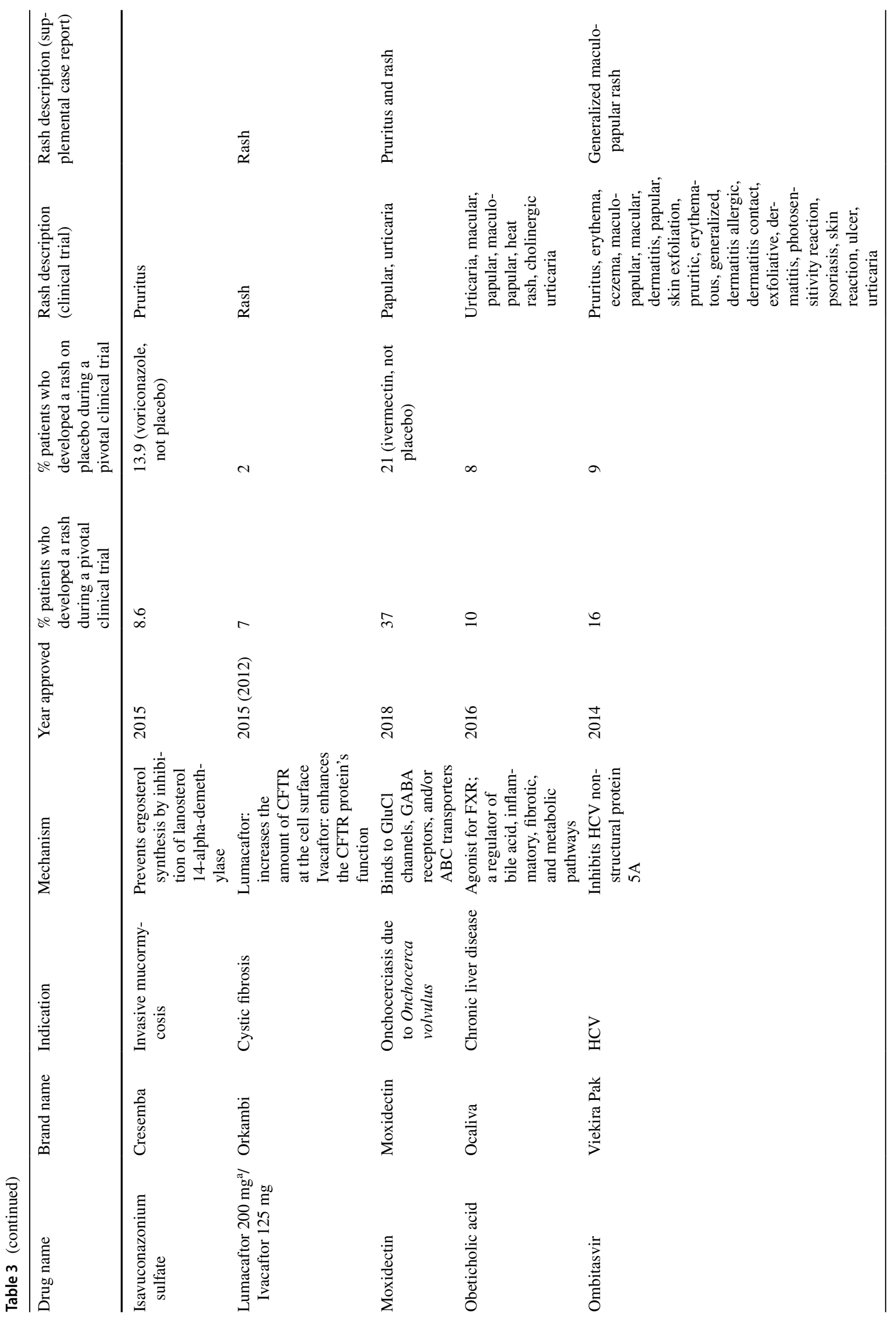




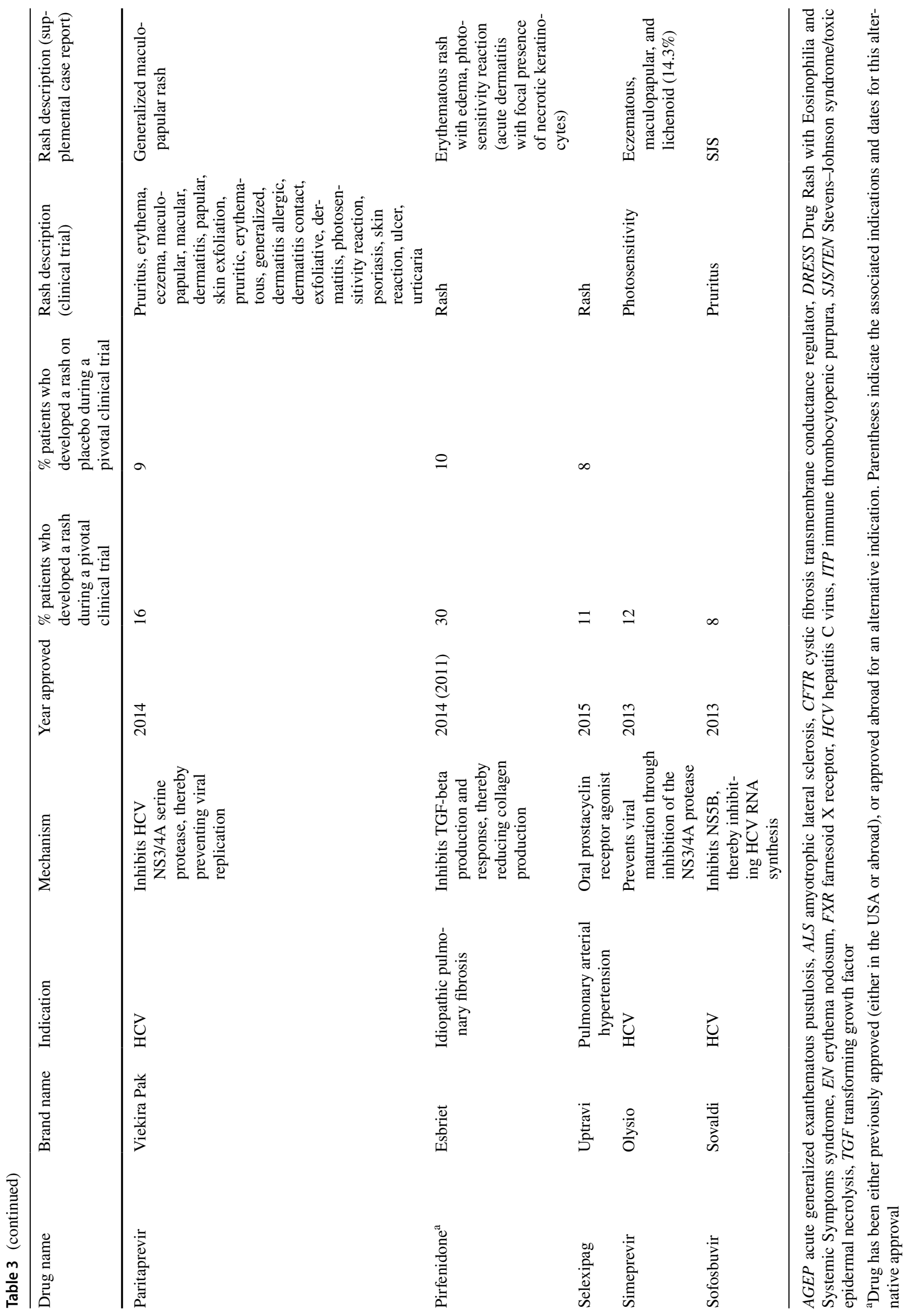


taking placebo. Details of the clinical trial indicate that the observed rash was described as generalized, maculopapular, papular, or pruritic [17]. A phase II, open-label multicenter study also noted rash as a side effect for $42 \%$ of patients taking siltuximab [18]. Additional case reports have not been published to supplement the clinical trial data.

\subsection{Small-Molecule Medications}

\subsubsection{Benznidazole}

Benznidazole, a nitroimidazole, was approved by the FDA in 2017 for the treatment of Chagas disease in children up to age 12 years. However, it has been utilized since the 1970s in Latin America [19], and has been available to clinicians in the USA through the Centers for Disease Control and Prevention since 2011 [20]. Its mechanism of action is unknown. Rashes were seen in $16 \%$ of patients taking benznidazole during clinical trials vs $0 \%$ of patients taking placebo [21]. The clinical trial did not offer further characterization of the rash.

A prospective descriptive study examining the effects of benznidazole treatment also describes an associated rash in $31.3 \%$ of patients and skin peeling in $25 \%$ of patients. In $15.6 \%$ of the patients, the rash was classified as skin eruptions that culminated in discontinuation of the drug [22]. Severe cutaneous adverse reactions such as acute generalized exanthematous pustulosis [23] and Drug Rash with Eosinophilia and Systemic Symptoms (DRESS syndrome) [24] have also been reported.

A prospective study found that dermatitis due to hypersensitivity was seen in $32.4 \%$ of patients taking benznidazole [25], and a supplemental case series describes the induced rash as a classic generalized morbilliform eruption, suggesting that patch testing may be beneficial in the confirmation of hypersensitivity reactions to benznidazole given its necessity in trypanosomiasis [26]. Interestingly, another nitroimidazole drug, metronidazole, has been reported to be a cross-reactor in several cases [26]. Additionally, a prospective observational study describes a drug eruption occurring in $38.5 \%$ of patients taking benznidazole [27].

\subsubsection{Cannabidiol (Epidiolex ${ }^{\circledast}$ )}

Cannabidiol oral solution was approved in 2018 to treat seizures associated with Lennox-Gastaut syndrome and Dravet syndrome. Its mechanism of action is unknown. Rashes were seen in $13 \%$ of patients taking cannabidiol during clinical trials vs $3 \%$ of patients taking placebo [28]. The clinical trial did not elaborate on the exact nature of the rash, but a case report describes an instance of acute generalized exanthematous pustulosis $48 \mathrm{~h}$ after self-medicating with over-the-counter oral cannabidiol for hypertension [29].

\subsubsection{Dimethyl Fumarate (Tecfidera ${ }^{\circledR}$ )}

Approved in 2013, dimethyl fumarate is a medication used to treat multiple sclerosis. It has also been approved to treat psoriasis in Europe [30], receiving approval from the European Medicines Agency in 2017 under the brand name Skilarence ${ }^{\circledR}$ [31]. Its mechanism of action is thought to involve activation of the nuclear erythroid 2-related factor 2 (nuclear factor erythroid-derived 2-like 2; Nrf2) transcriptional pathway. Rashes were seen in $8 \%$ of patients taking dimethyl fumarate during clinical trials vs $3 \%$ of patients taking placebo but did not result in treatment discontinuation [32]. Details of the clinical trial indicate that the observed rash was described as simply a rash. However, flushing was also noted in $40 \%$ of patients taking dimethyl fumarate vs $6 \%$ of patients taking placebo. It is believed that the flushing reaction described is most likely prostaglandin mediated and may be less visible or likely to develop in nonwhite populations [33]. A case report details an instance of erythema nodosum occurring in a woman after 6 years of dimethyl fumarate treatment [34]. Additional clinical trials have shown high rates of rashes $(23 \%)$ and pruritus $(8 \%)$ in children [35].

\subsubsection{Edaravone (Radicava ${ }^{\circledR}$ )}

Edaravone is a medication used to treat amyotrophic lateral sclerosis that was approved in 2017. Edaravone has also been approved for the treatment of acute ischemic stroke in Japan since 2009 [36]. It is believed to act as a free radical scavenger, thereby preventing oxidative stress damage to neurons. Rashes were seen in $8 \%$ of patients taking edaravone during clinical trials vs $5 \%$ of patients taking placebo [37]. Details of the clinical trial indicate that the observed rash was described as dermatitis or eczema.

\subsubsection{Fish Oil Triglycerides (Omegaven)}

Fish oil triglycerides as an injectable emulsion are used to treat parenteral nutrition-associated cholestasis. They were approved by the FDA in 2018 and act by providing a biologically utilizable source of calories and essential fatty acids. Rashes were seen in $8 \%$ of patients taking fish oil triglycerides during clinical trials [38]. The clinical trial did not elaborate on the exact nature of the rash and no specific case reports were found to offer further clarification. 


\subsubsection{Fostamatinib (Tavalisse ${ }^{\circledR}$ )}

Approved in 2018, fostamatinib is a medication used to treat immune thrombocytopenic purpura. Its mechanism of action involves inhibition of spleen tyrosine kinase (SYK). Rashes were seen in $9 \%$ of patients taking fostamatinib during clinical trials vs $2 \%$ of patients taking placebo. Details of the clinical trial indicate that the observed rash was described as a rash, with erythematous and macular features, suggesting a morbilliform reaction [39].

\subsubsection{Isavuconazonium Sulfate (Cresemba $\left.{ }^{\oplus}\right)$}

Isavuconazonium sulfate is a triazole antifungal medication used to treat invasive mucormycosis that was approved in 2015. Its mechanism of action involves inhibition of ergosterol synthesis by inhibiting the cytochrome P450-dependent enzyme, lanosterol 14-alpha-demethylase. Rashes were seen in $8.6 \%$ of patients taking isavuconazonium sulfate vs $13.9 \%$ of patients taking voriconazole [40]. Details of the clinical trial indicate that the observed rash was pruritic but without other descriptors. Given the active comparator had a higher rate of cutaneous disease, it is possible that a rash while taking isavuconazonium may be attributable to the high acuity of the treated infection, polypharmacy, or the overall complexity of treated patients who are often immunocompromised rather than the drug itself.

\subsubsection{Lumacaftor $200 \mathrm{mg} /$ /vacaftor $125 \mathrm{mg}$ (Orkambi ${ }^{\oplus}$ )}

Lumacaftor $200 \mathrm{mg}$ /ivacaftor $125 \mathrm{mg}$, approved in 2015, is a medication used to treat cystic fibrosis in children. This medication utilizes two active ingredients: lumacaftor and ivacaftor. While lumacaftor increases the amount of protein at the cell surface by targeting the defective F508del cystic fibrosis transmembrane conductance regulator protein, ivacaftor (which was approved by the FDA to treat cystic fibrosis in 2012 under the brand name Kalydeco ${ }^{\circledR}$ ) [41] enhances the cystic fibrosis transmembrane conductance regulator protein's function once it reaches the cell surface. Rashes were seen in $7 \%$ of patients taking lumacaftor $200 \mathrm{mg} / \mathrm{iva}-$ caftor $125 \mathrm{mg}$ during clinical trials vs $2 \%$ of patients taking placebo [42]. The clinical trial did not offer a description of the rash. An article detailing the phase III clinical trial for this medication also comments on the presence of a rash in one patient that resulted in discontinuation of the medication [43]. However, this article did not offer any further clarification regarding the nature of the rash.

\subsubsection{Moxidectin}

Moxidectin, approved in 2018, is a medication used to treat onchocerciasis due to Onchocerca volvulus. It binds to glutamate-gated chloride channels, gamma-aminobutyric acid receptors, and/or ATP-binding cassette transporters. Rashes were seen in $37 \%$ of patients taking moxidectin during clinical trials vs $21 \%$ of patients taking ivermectin. Details of the clinical trial indicate that the observed rash was described as a papular or urticarial [44]. A randomized controlled trial comparing moxidectin to ivermectin found that statistically significant higher percentages of participants treated with moxidectin experienced pruritus ( $87 \%$ vs $56 \%)$ and rash (63\% vs $42 \%)$ [45]. The study did not offer further characterization of the rash.

\subsubsection{Obeticholic Acid (Ocaliva ${ }^{\circledR}$ )}

Approved in 2016, obeticholic acid is a medication used to treat chronic liver disease. It is an agonist for farnesoid $\mathrm{X}$ receptor, a nuclear receptor expressed in the liver and intestine that regulates bile acid and inflammatory, fibrotic, and metabolic pathways. Rashes were seen in $10 \%$ of patients taking obeticholic acid during clinical trials vs $8 \%$ of patients taking placebo [46]. Details of the clinical trial indicate that the observed rash was described as urticarial, macular, papular, maculo-papular, heat rash, and cholinergic urticaria.

\subsubsection{Ombitasvir, Dasabuvir, and Paritaprevir (Viekira $\mathrm{Pak}^{\circledast}$ )}

Ombitasvir, dasabuvir, and paritaprevir are three medications that were approved by the FDA in 2014 to treat hepatitis $\mathrm{C}$ virus (HCV). They are used as a combination drug, along with ritonavir, in the commercial formulation "Viekira $\mathrm{Pak}^{\circledR}$ ". Ombitasvir is an inhibitor of the HCV non-structural protein 5A. Dasabuvir inhibits the action of NS5B palm polymerase, effectively terminating RNA polymerization and stopping the replication of the HCV's genome. Paritaprevir prevents $\mathrm{HCV}$ replication by inhibiting the HCV's NS3/4A serine protease. Rashes were seen in $16 \%$ of patients taking the combination of ombitasvir, dasabuvir, paritaprevir, and ritonavir vs $9 \%$ of patients taking placebo during clinical trials [47]. Details of the clinical trial indicate that the observed rash was described as eczematous, maculo-papular, macular, dermatitis, papular, pruritic, erythematous, generalized, allergic dermatitis, contact dermatitis, exfoliative, dermatitis, photosensitivity reaction, psoriasis, ulcers, and urticarial. A case report describes the development of a generalized maculopapular rash appearing 2 weeks after starting this antiviral treatment [48].

\subsubsection{Pirfenidone $\left(\right.$ Esbriet $\left.^{\circledR}\right)$}

Approved in 2014, pirfenidone is a medication used to treat idiopathic pulmonary fibrosis; an indication for which it was 


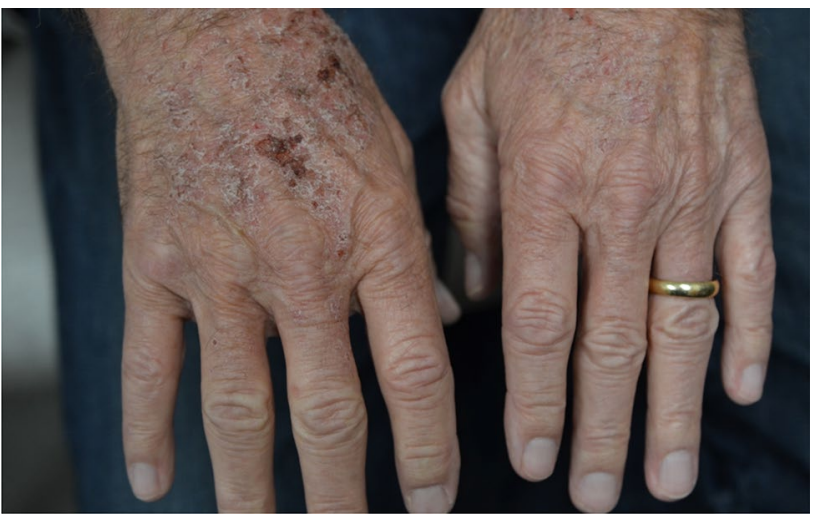

Fig. 2 Pirfenidone phototoxic drug eruption

approved in 2011 by the European Medicines Agency [49]. It reduces fibroblast proliferation by inhibiting the production of transforming growth factor-beta and reducing the collagen production stimulated by transforming growth factorbeta. Rashes were seen in $30 \%$ of patients taking pirfenidone during clinical trials vs $10 \%$ of patients taking placebo [50]. The clinical trial did not offer greater description of the rash, but a case report described the rash as erythematous with edema and noted that it occurred in $32 \%$ of patients taking pirfenidone vs $12 \%$ of patients taking placebo. A photosensitivity reaction (Fig. 2) was also noted in $12 \%$ of patients taking pirfenidone vs $2 \%$ of patients taking placebo, which was characterized histopathologically as acute dermatitis with focal presence of necrotic keratinocytes [51].

\subsubsection{Selexipag (Uptravi $\left.{ }^{\circledR}\right)$}

Selexipag is a medication used to treat pulmonary arterial hypertension that was approved in 2015. Selexipag is an oral prostacyclin receptor (IP receptor) agonist that is structurally distinct from prostacyclin. Rashes were seen in $11 \%$ of patients taking selexipag during clinical trials vs $8 \%$ of patients taking placebo [52]. The clinical trial described the cutaneous adverse reaction as simply a rash and no case reports offering further clarification were identified.

\subsubsection{Simeprevir (Olysio $\left.{ }^{\circledast}\right)$}

Simeprevir, approved in 2013, is a medication used to treat $\mathrm{HCV}$. It prevents viral maturation through inhibition of the NS3/4A protease. Rashes were seen in $12 \%$ of patients taking simeprevir during clinical trials [53]. The clinical trial described the reaction as a rash that included photosensitivity. A retrospective case series reports that patients taking simeprevir experienced rashes described as eczematous (28.6\%), maculopapular (57.1\%), and lichenoid (14.3\%) [54].

\subsubsection{Sofosbuvir (Sovaldi ${ }^{\circledR}$ )}

Sofosbuvir was approved in 2013 as a medication to treat HCV. Sofosbuvir inhibits the HCV NS5B protein, thereby inhibiting viral RNA synthesis. Rashes were seen in $8 \%$ of patients taking sofosbuvir during clinical trials [55]. Details of the clinical trial indicate that the observed rash was described as a rash and pruritus. A case report detailed an instance of Stevens-Johnson syndrome 10 days after initiating sofosbuvir therapy [56].

\section{Conclusions}

Of the 241 medications approved by the FDA between 2013 and 2018, 21 of the non-chemotherapeutic agents were associated with a prominent rate of cutaneous adverse events. Most reactions were classified as morbilliform, macular, popular, or maculopapular. This study was largely limited by the frequently vague and non-specific rash reporting found in the medication package inserts as well as the available case reports. Notably, the lack of specificity in the FDA package inserts highlights the importance of dermatologists reporting adverse events during clinical trials and post-marketing surveillance. Trials should consider engaging with dermatology experts to provide more granular detail of drug reactions when skin toxicities appear common. Fortunately, only a few severe cutaneous adverse reactions have been reported, namely in benznidazole, cannabidiol, and sofosbuvir. When suspicious, careful history taking of any additions or changes to a patient's medication regimen is an important component of the dermatology assessment. Familiarization with these new therapeutics including understanding their indications and who may be treated should help dermatologists and referring physicians to recognize drug reactions early.

\section{Compliance with Ethical Standards}

Funding No funding was received for the preparation of this article.

Conflict of interest Benjamin H. Kaffenberger is an investigator and funded by the Dermatology Foundation in the investigation of drug eruptions. Paul C. Macklis, Brittany Dulmage, Brady Evans, Misha Rosenbach, and Johann E. Gudjonsson have no conflicts of interest that are directly relevant to the content of this article.

Open Access This article is licensed under a Creative Commons Attribution-NonCommercial 4.0 International License, which permits any non-commercial use, sharing, adaptation, distribution and reproduction in any medium or format, as long as you give appropriate credit to the original author(s) and the source, provide a link to the Creative Commons licence, and indicate if changes were made. The images or other third party material in this article are included in the article's Creative Commons licence, unless indicated otherwise in a credit line to the material. If material is not included in the article's Creative Commons 
licence and your intended use is not permitted by statutory regulation or exceeds the permitted use, you will need to obtain permission directly from the copyright holder. To view a copy of this licence, visit http://creativecommons.org/licenses/by-nc/4.0/.

\section{References}

1. Biswal SG, Mehta RD. Cutaneous adverse reactions of chemotherapy in cancer patients: a clinicoepidemiological study. Indian J Dermatol. 2018;63(1):41-6. https://doi.org/10.4103/ijd. IJD_65_17.

2. Ng CY, Chen C-B, Wu M-Y, et al. Anticancer drugs induced severe adverse cutaneous drug reactions: an updated review on the risks associated with anticancer targeted therapy or immunotherapies. J Immunol Res. 2018;17(2018):5376476.

3. Rosen AC, Balagula Y, Raisch DW, et al. Life-threatening dermatologic adverse events in oncology. Anticancer Drugs. 2014;25(2):225-34. https://doi.org/10.1097/CAD.0000000000 000032 .

4. EMA. Zenapax [prescribing information]. https://www.ema.europ a.eu/en/documents/product-information/zenapax-epar-productinformation_en.pdf. Accessed 12 May 2020.

5. MPR. Roche discontinues Zenapax injection. Published 22 December, 2009. https://www.empr.com/home/news/roche-disco ntinues-zenapax-injection/. Accessed 12 May 2020.

6. GOV.UK. Daclizumab beta (Zinbryta $\boldsymbol{\nabla}$ ): risk of immune-mediated encephalitis: some cases several months after stopping treatment. https://www.gov.uk/drug-safety-update/daclizumab-betazinbryta-risk-of-immune-mediated-encephalitis-some-cases-sever al-months-after-stopping-treatment. Accessed 12 May 2020.

7. Huss DJ, Mehta DS, Sharma A, et al. In vivo maintenance of human regulatory $\mathrm{T}$ cells during $\mathrm{CD} 25$ blockade. J Immunol. 2015;194(1):84-92. https://doi.org/10.4049/jimmunol.1402140.

8. US FDA. Zinbryta (daclizumab) injection, for subcutaneous use [prescribing information]. https://www.accessdata.fda.gov/drugs atfda_docs/label/2017/761029s007lbl.pdf. Accessed 22 Dec 2019.

9. Lockhart A, Kirby B, McGuigan C. Rash developing after cessation of daclizumab for relapsing remitting MS; a case series. Mult Scler Relat Disord. 2019;35:239-40. https://doi.org/10.1016/j. msard.2019.08.008.

10. US FDA. Dupixent (dupilumab) injection. https://www.accessdata .fda.gov/drugsatfda_docs/label/2017/761055lbl.pdf. Accessed 22 Jan 2020.

11. de Wijs LEM, Nguyen NT, Kunkeler ACM, Nijsten T, Damman J, Hijnen DJ. Clinical and histopathological characterization of paradoxical head and neck erythema in patients with atopic dermatitis treated with dupilumab: a case series. Br J Dermatol. 2019. https ://doi.org/10.1111/bjd.18730.

12. Waldman RA, DeWane ME, Sloan B, Grant-Kels JM. Characterizing dupilumab facial redness: a multi-institution retrospective medical record review. J Am Acad Dermatol. 2020;82(1):230-2. https://doi.org/10.1016/j.jaad.2019.06.026.

13. Soria A, Du-Thanh A, Seneschal J, Jachiet M, Staumont-Sallé D, Barbarot S. Development or exacerbation of head and neck dermatitis in patients treated for atopic dermatitis with dupilumab. JAMA Dermatol. 2019;155(11):1312-5. https://doi.org/10.1001/ jamadermatol.2019.2613.

14. de Beer FSA, Bakker DS, Haeck I, et al. Dupilumab facial redness: positive effect of itraconazole. JAAD Case Rep. 2019;5(10):88891. https://doi.org/10.1016/j.jdcr.2019.07.020.

15. Belhomme N, Gaignon T, Jouneau S, et al. Drug-induced granulomatosis: is dupilumab the new kid on the block? J Eur Acad Dermatol Venereol. 2020. https://doi.org/10.1111/jdv.16218.
16. US FDA. Trogarzo ${ }^{\mathrm{TM}}$ (ibalizumab-uiyk) injection [prescribing information]. https://www.accessdata.fda.gov/drugsatfda_docs/ label/2018/761065lbl.pdf. Accessed 22 Dec 2019.

17. US FDA. Sylvant (siltuximab) [prescribing information]. Available from: https://www.accessdata.fda.gov/drugsatfda_docs/label /2014/125496s000lbl.pdf. Accessed 23 Dec 2019.

18. van Rhee F, Casper C, Voorhees PM, et al. A phase 2, open-label, multicenter study of the long-term safety of siltuximab (an antiinterleukin-6 monoclonal antibody) in patients with multicentric Castleman disease. Oncotarget. 2015;6(30):30408-199.

19. CDC. Chagas disease: what US clinicians need to know. https:// www.cdc.gov/parasites/cme/chagas/lesson_3/20.html. Accessed 12 May 2020.

20. Infectious Disease Advisor. CDC advises that benznidazole now only available through drug company. Published 27 August, 2018. Available from: https://www.infectiousdiseaseadvisor.com/home/ topics/vector-borne-illnesses/cdc-advises-that-benznidazolenow-only-available-through-drug-company/. Accessed 12 May 2020.

21. US FDA. Benznidazole tablets, for oral use. https://www.acces sdata.fda.gov/drugsatfda_docs/label/2017/209570lbl.pdf. Accessed 31 Dec 2019.

22. de Pontes VMO, de Souza Júnior AS, da Cruz FMT, et al. Adverse reactions in Chagas disease patients treated with benznidazole, in the State of Ceará [in Portuguese]. Rev Soc Bras Med Trop. 2010;43(2):182-7. https://doi.org/10.1590/s0037 -86822010000200015 .

23. ScienceDirect. Acute generalized exanthematous pustulosis due to benznidazole. https://www.sciencedirect.com/science/artic le/abs/pii/S2213219814003833?via\%3Dihub. Accessed 10 Jan 2020.

24. González-Ramos J, Noguera-Morel L, Tong HY, et al. Two cases of overlap severe cutaneous adverse reactions to benznidazole treatment for asymptomatic Chagas disease in a nonendemic country. Br J Dermatol. 2016;175(3):604-7. https://doi. org/10.1111/bjd.14451.

25. Carrilero B, Murcia L, Martinez-Lage L, Segovia M. Side effects of benznidazole treatment in a cohort of patients with Chagas disease in non-endemic country. Rev Esp Quimioter. 2011;24(3):123-6.

26. Noguerado-Mellado B, Rojas-Pérez-Ezquerra P, Calderón-Moreno M, Morales-Cabeza C, Tornero-Molina P. Allergy to benznidazole: cross-reactivity with other nitroimidazoles. J Allergy Clin Immunol Pract. 2017;5(3):827-8. https://doi.org/10.1016/j. jaip.2016.09.047.

27. Salvador F, Sánchez-Montalvá A, Martínez-Gallo M, et al. Evaluation of cytokine profile and HLA association in benznidazole related cutaneous reactions in patients with Chagas disease. Clin Infect Dis. 2015;61(11):1688-94. https://doi.org/10.1093/cid/ civ690.

28. US FDA. Epidiolex ${ }^{\circledR}$ (cannabidiol) oral solution [prescribing information]. https://www.accessdata.fda.gov/drugsatfda_docs/ label/2018/210365lbl.pdf. Accessed 27 Dec 2019.

29. Pettit C, Massick S, Bechtel M. Cannabidiol-induced acute generalized exanthematous pustulosis. Dermatitis. 2018;29(6):345-6. https://doi.org/10.1097/DER.0000000000000422.

30. Blair HA. Dimethyl fumarate: a review in moderate to severe plaque psoriasis. Drugs. 2018;78(1):123-30. https://doi. org/10.1007/s40265-017-0854-6.

31. EMC. Skilarence $120 \mathrm{mg}$ gastro-resistant tablets: summary of product characteristics (SmPC). https://www.medicines.org.uk/ emc/product $/ 7480 / \mathrm{smpc}$. Accessed 12 May 2020.

32. US FDA. Tecfidera ${ }^{\circledR}$ (dimethyl fumarate) delayed-release capsules, for oral use [prescribing information]. https://www.tecfi dera.com/content/dam/commercial/tecfidera/pat/en_us/pdf/fullprescribing-info.pdf. Accessed 31 Dec 2019. 
33. Ochi H, Niino M, Onizuka Y, et al. 72-week safety and tolerability of dimethyl fumarate in Japanese patients with relapsing-remitting multiple sclerosis: analysis of the randomised, double blind, placebo-controlled, phase III APEX study and its open-label extension. Adv Ther. 2018;35(10):1598-611. https://doi.org/10.1007/ s12325-018-0788-8.

34. Algahtani H, Shirah B, Marghalani S, Algarni A. Erythema nodosum in a patient with multiple sclerosis on dimethyl fumarate. Mult Scler Relat Disord. 2019;28:155-8. https://doi.org/10.1016/j. msard.2018.12.032.

35. Makhani N, Schreiner T. Oral dimethyl fumarate in children with multiple sclerosis: a dual-center study. Pediatr Neurol. 2016;57:101-4. https://doi.org/10.1016/j.pediatrneu rol.2016.01.010.

36. Miyahi Y, Yoshimura S, Sakai N, et al. Effect of edaravone on favorable outcome in patients with acute cerebral large vessel occlusion: subanalysis of RESCUE-Japan Registry. Neurol Med Chir (Tokyo). 2015;55(3):241-7. https://doi.org/10.2176/nmc. ra.2014-0219.

37. US FDA. Radicava (edaravone injection), for intravenous use. https://www.accessdata.fda.gov/drugsatfda_docs/label /2017/209176lbl.pdf. Accessed 31 Dec 2019.

38. US FDA. Omegaven (fish oil triglycerides) injectable emulsion [prescribing information]. https://www.accessdata.fda.gov/drugs atfda_docs/label/2018/0210589s000lbledt.pdf. Accessed 27 Dec 2019.

39. US FDA. Tavalisse ${ }^{\mathrm{TM}}$ (fostamatinib disodium hexahydrate) tablets, for oral use [prescribing information]. https://www.accessdata.fda. gov/drugsatfda_docs/label/2018/2092991bl.pdf. Accessed 23 Dec 2019.

40. US FDA. Cresemba (isavuconazonium sulfate) [prescribing information]. https://www.astellas.us/docs/cresemba.pdf. Accessed 31 Dec 2019.

41. US FDA. Press announcements. FDA approves Kalydeco to treat rare form of cystic fibrosis. https://web.archive.org/web/20160 318062836/https://www.fda.gov/NewsEvents/Newsroom/Press Announcements/ucm289633.htm. Accessed 12 May 2020.

42. US FDA. Orkambi ${ }^{\circledR}$ (lumacaftor/ivacaftor) tablets, for oral use Orkambi $^{\circledR}$ (lumacaftor/ivacaftor) oral granules [prescribing information]. Available from: https://pi.vrtx.com/files/uspi_lumacaftor _ivacaftor.pdf. Accessed 31 Dec 2019.

43. Milla CE, Ratjen F, Marigowda G, et al. Lumacaftor/ivacaftor in patients aged 6-11 years with cystic fibrosis and homozygous for F508del-CFTR. Am J Respir Crit Care Med. 2017;195(7):912-20. https://doi.org/10.1164/rccm.201608-1754OC.

44. US FDA. Moxidectin [prescribing information]. https://www. accessdata.fda.gov/drugsatfda_docs/label/2018/2108671bl.pdf. Accessed 23 Dec 2019.
45. Awadzi K, Opoku NO, Attah SK, Lazdins-Helds J, Kuesel AC. A randomized, single-ascending-dose, ivermectin-controlled, double-blind study of moxidectin in Onchocerca volvulus infection. PLoS Negl Trop Dis. 2014;8(6):e2953. https://doi.org/10.1371/ journal.pntd.0002953.

46. US FDA. Ocaliva (obeticholic acid) tablets, for oral use [prescribing information]. https://www.accessdata.fda.gov/drugsatfda _docs/label/2016/207999s000lbl.pdf. Accessed 31 Dec 2019.

47. US FDA. Viekira Pak (ombitasvir, paritaprevir, and ritonavir tablets; dasabuvir tablets) [prescribing information]. https://www. accessdata.fda.gov/drugsatfda_docs/label/2014/2066191bl.pdf. Accessed 31 Dec 2019

48. Navarro-Triviño FJ, Muñoz-Medina L, Navarro-Navarro I, RuizVillaverde R. Cutaneous eruptions by new therapies against hepatitis $\mathrm{C}$ virus infection: not as common as we presumed. Int $\mathrm{J}$ Dermatol. 2018;57(4):493-4. https://doi.org/10.1111/ijd.13882.

49. Genentech. Esbriet ${ }^{\circledR}$ (pirfenidone): information for patients. https ://www.gene.com/patients/medicines/esbriet. Accessed 12 May 2020.

50. Genentech. Esbriet ${ }^{\circledR}$ (pirfenidone) capsules and film-coated tablets, for oral use [prescribing information]. https://www.gene.com/ download/pdf/esbriet_prescribing.pdf. Accessed 31 Dec 2019.

51. Ferrer Guillén B, Giácaman MM, Valenzuela Oñate C, Magdaleno Tapial J, Hernández Bel P, Pérez FA. Pirfenidone-induced photosensitivity confirmed by pathological phototest. Photodiagn Photodyn Ther. 2019;25:103-5. https://doi.org/10.1016/j.pdpdt .2018.11.015.

52. US FDA. Uptravi ${ }^{\circledR}$ (selexipag) tablets, for oral use [prescribing information]. https://www.accessdata.fda.gov/drugsatfda_docs/ label/2015/207947s000lbl.pdf. Accessed 31 Dec 2019.

53. US FDA. Olysio (simeprevir) capsules, for oral use [prescribing information]. https://www.accessdata.fda.gov/drugsatfda_docs/ label/2017/205123s012lbl.pdf. Accessed 31 Dec 2019.

54. Borgia F, Cacciola I, Filomia R, Vaccaro M, Squadrito G, Cannavò SP. Mucocutaneous toxicity during simeprevir treatment for hepatitis $\mathrm{C}$ : a single institution, retrospective case series. $\mathrm{Br}$ J Clin Pharmacol. 2017;83(5):1152-4. https://doi.org/10.1111/ bcp. 13221.

55. US FDA. Sovaldi ${ }^{\circledR}$ (sofosbuvir) tablets, for oral use [prescribing information]. https://www.gilead.com/ /media/Files/pdfs/medic ines/liver-disease/sovaldi/sovaldi_pi.pdf. Accessed 31 Dec 2019.

56. Verma N, Singh S, Sawatkar G, Singh V. Sofosbuvir induced Steven Johnson syndrome in a patient with hepatitis C virusrelated cirrhosis. Hepatol Commun. 2018;2(1):16-20. https:// doi.org/10.1002/hep4.1126. 